\title{
Maternal Health Care Information for Improving Access to Maternal Health Services for Adolescent Girls and Young Women (AGYW) in Lower-and- Middle Income Countries
}

\author{
Joyce T. Shatilwe ${ }^{1}$, Tivani P. Mashamba-Thompson ${ }^{1} \&$ Desmond Kuupiel $^{2}$ \\ ${ }^{1}$ Discipline of Public Health, School of Nursing and Public Health, University of KwaZulu-Natal, Durban, South \\ Africa \\ ${ }^{2}$ Department of Public Health, University of Limpopo, Polokwane, Limpopo Province, South Africa \\ Correspondence: Joyce T. Shatilwe, Discipline of Public Health, School of Nursing and Public Health, University \\ of KwaZulu-Natal, Durban 4001, South Africa. E-mail: jshatilwe@hotmail.com
}

Received: December 25, 2019 Accepted: January 19, 2020 Online Published: April 29, 2020

doi:10.5539/gjhs.v12n6p145

URL: https://doi.org/10.5539/gjhs.v12n6p145

\begin{abstract}
Background: There is a dire need to uplift the well-being of pregnant adolescent girls and young women through development and implementation of strategies that can reduce barriers to access maternal healthcare services. This in return will reduce pregnancy related complications which is a threat to many adolescents especially in developing countries.
\end{abstract}

Findings: Other stakeholders such as community members are less involved in the activities of AGYW. Information is not enough to cater for the health needs of AGYW. There are less policies and law in place that will guide the AGYW to make informed decisions. Young people, need to be provided with quality education, training, health information and services to enable them to make informed decisions. Furthermore, their rights need to be protected. They also need to be granted with opportunities to participate in decision making and to equip them for the future. This will enable them to participate in the affairs of their communities and contribute to economic development (UNFPA, 2014, 2017b; WHO, 2015a).

Conclusion: Poor access to maternal health care information by young women may lead to poor use of maternal healthcare services and maternal outcomes. Maternal healthcare information have been used as a strategy to improve maternal healthcare services to reduce the risk of complications during pregnancy.

This review therefore provided an overview on healthcare information that enable access and utilize of maternal healthcare services by adolescent and young women during pregnancy in Lower-and-Middle Income Countries (LMICs). Barriers relating to accessing and utilizing maternal healthcare services by young women in LMICs were also discussed. This review has additionally recommended creative interventions for conquering these obstructions to help improve maternal health outcomes in Lower and Middle Income Countries.

Keywords: access, maternal health, adolescent girl, young women, healthcare information, lower-and-middle income countries

\section{Introduction}

Maternal Health care information is an important component that plays a major role to save the lives of many adolescent girls and young women if well implemented. Maternal health care information is the information provided to women before pregnancy, during pregnancy, childbirth and the post-pregnancy period (USAID, 2016; WHO, 2015a).

Poor maternal, new-born and child healthcare remains a significant problem in low-and-middle income countries (LMICs) (Z. Lassi, Mansoor, Salam, Das, \& Bhutta, 2014). Globally, it is estimated that 250000 to 280000 women die during pregnancy (Z. S. Lassi, Tarab, Salam, \& Bhutta, 2014). Albeit worldwide fertility rates have dropped extensively in the most recent decades, numerous adolescents between the ages of 15 to 19 have just started bearing children with varieties existing between countries (Plan International, 2017). Of all annual births worldwide, $11 \%$ occur in girls aged between 15 to 19 years (UNICEF, 2017). This translates to approximately 16 million births amongst adolescents. Of those 16 million births, 95\% occur in LMICs (UNICEF, 2017). Early 
pregnancy and labour can have genuine wellness and social outcomes due to complications and it is the second complication for death among adolescent girls and young women (AGYW) (UNESCO, 2018). Adolescent girls have a greater risk of dying from childbirth compared to women in their early 20s (Chandra-Mouli et al., 2015b). Their children will in general have lower birth weight, more health problems, and they are also vulnerable to neonatal death (Chandra-Mouli et al., 2015b). This review provides an overview of literature on maternal health care information for improving access to maternal health care services for adolescent and young women in LMICs. This literature review also highlighted the effectiveness of these maternal health care information on enabling access to and use of maternal healthcare services by AGYW during pregnancy in LMICs. Challenges and barriers to accessing and utilizing maternal health care information systems by AGYW during pregnancy in LMICs have also been discussed. The following databases were searched for relevant literature: Google Scholar, PubMed, EBSCOhost and Emerald.

\section{Interventions Enabling Access to Healthcare Information in LMICs}

\subsection{Health Promotion Programmes}

According to the World Health Organization (WHO), health promotion is regarded as the way towards empowering individuals to expand command over and to improve their health (WHO, 2015c). Health promotion does not only pays emphasis on individual behaviour, but it also look at the scope of social and ecological interventions (Kuhlmann, Altmana, \& Galavottic, 2016; WHO, 2015c). Health promotion programs need to concentrate on individual practices, supplemented by help, education, strengthening and maternal health administration programs situated in schools, families and networks (including conventional and religious frameworks) (Smith, Portela, \& Marston, 2017; WHO, 2015c). The WHO guidelines on health promotion interventions for maternal and new born health $(\mathrm{MNH})$ recommends a progression of interrelated interventions to improve access to and utilization of talented care during pregnancy, labour and after birth (WHO, 2015c). Interventions firmly suggested and could be actualized in various settings are as per the following: Birth readiness and complexities readiness, male association and organization with conventional birth attendants. Other interventions are socially suitable skilled maternity care, companion of choice during childbirth. Community involvement and support in quality improvement strategies and in program planning and evaluation intercessions are also crucial (Department of Health, 2017; World Health Organisation).

\subsection{Community-Based Interventions}

Social change and public involvement, engagement and preparation are expanding regular techniques in public health. These approaches are highly accepted due to somewhat similar expectations that they produce better health results among the objective populations and result in longer-term manageability of program exercises and impacts (Kuhlmann et al., 2016). It is imperative to draw in not just with women of reproductive age and their families, yet additionally with different individuals from their communities to build up an empowering atmosphere, remembering cultivating changes for more extensive social standards to improve care activities (Smith et al., 2017). Approaches to support this commitment included utilizing broad communications to bring issues to light or activate communities, and including communities in creating materials, for example, pamphlets utilized in health promotion interventions (Smith et al., 2017). These were accounted for to have made positive community perceptions of interventions (Miltenburg, Roggeveen, van Roosmalen, \& Smith, 2017), and expanded mindfulness and take-up of demand-side financing programmes (Department of Health, 2017; B. Hunter \& S. Murray, 2017).

Interventions announced to improve care seeking outcomes frequently included social preparation exercises to produce community support, incorporating associations with customary birth attendants (Miller \& Smith, 2017), and individuals from the more extensive community, for example, religious leaders and men (George \& Branchini, 2017). Drawing in the more extensive community can empower shared understandings and arrangements around medical issues to be created and executed. For example, religious and community leader commitment was seen as essential in growing new roles for traditional birth attendants (Miller \& Smith, 2017) and in elevating the privilege to maternity care services (George \& Branchini, 2017). Creation of awareness may be done through the collaboration with public leadership in setting up youth friendly services and through youth open days advancing adolescent sexual and reproductive health, for example, condom use and HIV testing (L. Gottschalk \& Ortayli, 2014). Involvement of the community to participate in issues related to their community is significant in understanding the existing services and potential arrangements from the community viewpoint, and in the advancement and usage of interventions (Jones, Lattof, \& Coast, 2017).

\subsection{National Policy}

United Nation Population Fund (UNFPA) has upheld improvement of different policy documents and guidelines 
comprehensive of the essential and secondary life skills, HIV and AIDS education tactics, national Adolescents and Sexual Reproductive Health (ASRH) strategy and interventions, and research and assessments (Miltenburg et al., 2017; UNFPA, 2017 b). Approaches on the privileges of individuals younger than 18 years control whether teenagers have the right to settle on their own choices with respect to sexual and reproductive health or whether they need permission from their parents or spouses (Glinski, Sexton, \& Petroni, 2014; Marleen, 2015). Laws and strategies have to play a major role in the set up and realization of health and human rights by women and young girls, including sexual and reproductive health (SRH) rights. National and sub-national legal and policy frameworks need to link up with acknowledged human rights' standards and principles, and nations ought to build up or strengthen instruments to actualize these standards (Haberland \& Rogow, 2015b; PSI, 2017).

\subsection{Access to Educational Programmes}

Increased access to education is part of some of the prioritized initiatives made by governments to strengthen human capital, especially past the primary level. Arrangements that guarantee young individuals' entrance to health, including sexual and reproductive health are regarded as very crucial (UNFPA, 2014, 2017b, 2017a). Young individuals, for example, teenagers need quality education, training, health information and services as well as human rights protections. Furthermore, they need to be provided with opportunities to partake in basic leadership to prepare them in decision making. This will empower them to take part in the issues of their community and add to economic growth (UNFPA, 2014, 2017a, 2017b).

\subsection{Demand-Side Programmes}

These are programs to improve parent-teen communication. Programs must draw parents' attention to the vital importance of building strong bonds with adolescents (Ministry of Health and Social Services \& UNICEF, 2017; UNFPA, 2017a). Adolescents who expects to be later successful in a job are statistically more likely to delay sexual debut (Marleen, 2015). Schools can improve students' experiences with curricular and extracurricular efforts to build each child's unique talents, to impart the soft skills needed to foster resilience and to facilitate the social integration of all learners in the system (Ministry of Health and Social Services \& UNICEF, 2017). Adolescent who live in poor communities may lack objective incentives to stay in school and delay sexual debut. Instead, they may embrace early marriage or motherhood/fatherhood as a strategy to consolidate an alternative identity (B. M. Hunter \& S. F. Murray, 2017; Ministry of Health and Social Services \& UNICEF, 2017).

\subsection{Adolescent Friendly Health Services}

The World Health Organization describes an adolescent as any person between 10 to 19 years (WHO, 2017). Worldwide statistics show that $11 \%$ (approximately 16 million births) of all annual births occur among young girls between the ages of 15 to 19 years (WHO, 2014). Of these 16 million annual births among adolescents, 95 percent occur in LMICs. Sub-Saharan Africa (SSA) has the highest birth rates amongst adolescents with 200 per 1000 births (UNICEF, 2017). Adolescent friendly health services (AFHS) include procedures, practices, and other attributes that attract all adolescents of varied ages, and provide them with a comfortable and appropriate setting, meeting their health needs, and are able to retain them for follow-up and repeat visits (UNFPA, 2017a). AFHS are free from barriers that would otherwise limit access by adolescents (WHO, 2014a). This is achieved by creating a supportive social, cultural and political climate that is more responsive to the special sexual and reproductive health needs of adolescents and youth as a group (UNFPA, 2017a). An adolescent friendly environment offers services in a comfortable, acceptable, accessible manner and ensures privacy and confidentiality. It also takes into consideration the unique nature of adolescents as well as their physical, psychological, and emotional development (UNFPA, 2017b).

There are six (6) components that can be considered for implementing AFHS such as adolescent participation, community support and participation, AFHS providers, adolescent friendly environment, adolescent friendly procedures and networking and collaboration (UNFPA, 2017a). Youth advancement and life skills training have numerous advantages, for example, improved Sexual and Reproductive Health (SRH) results, depending on the unique situation and how projects are put into place. Given the social and cultural barriers to youngsters' SRH, youth-friendly services projects should keep on being a focal point of study (Haberland \& Rogow, 2015b; Merrick, 2015; The Guttmacher Institute, 2015b). Adolescents face sociocultural obstacles when it comes to accessing SRH information and services, so these activities were aimed at fostering for those obstacles (Glinski et al., 2014; L. B. Gottschalk, 2014; UNESCO, 2018).

\subsection{Comprehensive Sexuality Education}

Evidence-based health information and comprehensive sexuality education (CSE) are some of the key interventions for advancement and protection of women's health (UNFPA, 2014). CSE gives intensive, logically 
precise, non-critical information and helps individuals to create aptitudes for basic leadership, basic reasoning, correspondence, and exchange of relational connections (Haberland \& Rogow, 2015b; PSI, 2017). CSE programs are more cost effective than single-issue interventions, yet to accomplish conduct change, we should find out about contrasts between the effective projects and the ones that are unsuccessful (14). Sexuality education that is complete as opposed to concentrated on a solitary issue by and large expands information, yet a substantive minority of projects don't change conduct (Haberland \& Rogow, 2015a). The CSE programs do change conduct and can postpone sexual presentation, lessen recurrence of sex and number of partners, and increment the utilization of condoms or different contraceptives. Youngsters would be most open to discussing SRH with companions or their peers (Haberland \& Rogow, 2015b; Miltenburg et al., 2017; Svanemyr, Amin, Robles, \& Greene, 2015). Programmes organizers need to focus on how peer education programs are planned and actualized to relevant variables that impact their adequacy (L. B. Gottschalk, 2014; Marleen, 2015; Merrick, 2015; PSI, 2017).

\subsection{Media}

The power and practicality of health technology can be utilized to its maximum advantage for health training, data and support (Department of Health, 2017). A few projects enhanced their primary activities with different types of media to expand information on SRH themes, attention to administrations and worthiness among young people and the wider community (PSI, 2017). This include a number of media seen usually all through information, education and communication mediums, for example, posters, handouts, shows, new letters and a radio programmes (Department of Health, 2017; B. Hunter \& S. Murray, 2017). Broad communications campaigns are progressively effective when they utilize various channels and are joined with different interventions conveyed at clinics and schools - making messages about service-seeking for increasingly significant (Glinski et al., 2014; Svanemyr et al., 2015). Scaling up Information and Technology (IT) stages do advance commitment and active participation of youth with the health service. It further widens and reinforces advanced channels of education and Information (LeFevre et al., 2018). This is upheld by utilizing versatile advancements, make health information applications, health observing instruments and patient input strategies (Department of Health, 2017; B. Hunter \& S. Murray, 2017).

\section{Access to Maternal Healtheare Information by AGYW in LMICs}

According to the World Health Organizations, only a few interventions exists in aiding young adolescents, however the few that do exists do not cater for the majority. This is because there is less contacts between the health system and adolescent (WHO, 2015b, and 2015c).

Access to youth friendly health services is fundamental for ensuring SRH and well-being of adolescents (Denno, Hoopes, \& Chandra-Mouli, 2015). There is most sufficient information on approaches that use a combination of health worker training, adolescent friendly facility improvements and broad information broadcasting via the community, schools and mass media (Denno et al., 2015). Strategies that are geared towards pregnancy and improvement of health care are very critical to prevent complications during pregnancy among adolescent women in LMICs (Ganchimeg et al., 2014).

Demand-side approaches are recognized to have positive influence on the utilization of health services and in return they have evidence on the reduction of early neonatal and maternal mortality (Hurst, Semrau, Patna, Gawande, \& Hirschhorn, 2015). Nations are recognising the importance of equipping young people with the information and abilities necessary to assist them in making informed decisions, especially in settings where new information and communication technologies (ICTs) and online networking play an unquestionably significant role in their lives for instance: Access to Information and pictures identifying with sexual activities are readily available on the web. Likewise, they can be the key presentation to sexuality or sexuality training for some children and young people (UNESCO, 2018; UNFPA, 2017a). Information, Communication and Technologies and social media have an important function to play in the increase of accurate, positive and non-judgmental information on reproductive health (UNESCO, 2018). On the other hand, information from technology may be inaccurate and inappropriate to young people in the sense that it may lead to harmful gender norms and it may expose this group to access often violent pornography (UNESCO, 2018).

A vital factor of universal health coverage is the accessibility of quality healthcare without experiencing financial adversity (WHO, 2017). The probability of poorer adolescent girl and young women (AGYW) to receive care is less compared to that of wealthier AGYW, which in turn leads to major inconsistencies in health outcomes and the essential concentration on equity (Charaborty \& Sprockett, 2018; WHO, 2017). The documenting of the inequity in access to quality health care along with achievement of health outcomes by wealth status and area of residence has been noted (UNDP, 2018). 


\subsection{Utilization of Maternal Health Care Services by AGYW in LMICs.}

The education of the adolescent mother and her partner was observed to be the most important factor influencing the maternal health services utilization (Banke-Thomas, Banke-Thomas, \& Ameh, 2017). It is of vital importance to strengthen and upgrade the adolescent girl child's education and eradicate any financial barriers to access maternal health services (Eniola, Oluwabusayo, \& Ameh, 2017). These are critical in improving adolescent maternal health services utilization (Eniola et al., 2017). It is imperative that all pregnant adolescent girls be educated on the importance of receiving professional antenatal care. Women who receive sufficient antenatal care are probable to be involved in other important services, including institutional delivery (The Guttmacher Institute, 2015b). Antenatal care and institutional delivery are of vital importance in identifying and addressing complications, thus preventing maternal morbidity and mortality (Eniola et al., 2017; Melaku et al., 2014; Mheta \& Mashamba-Thompson, 2017; The Guttmacher Institute., 2015a). Evaluating antenatal care and institutional pregnancy services utilization and their factors is a vital step towards improving maternal health care services (Eniola et al., 2017). Factors such as wealth quantile, broad casting coverage and rural/urban residence were common major factors that may have influence on maternal health service utilization (Eniola et al., 2017).

\subsection{Challenges to Accessing Maternal Healthcare Information by AGYW in LMICs}

In most Latin American and Caribbean countries, more than 50 per cent of recent births to women under 20 years are unplanned. In a third of African countries, the proportion of births to women is 40 per cent (WHO, 2017). The leading cause of death among adolescent girls aged 15-19 worldwide is suicide. Poor SRH is among the most important contributors to poor mental health (WHO, 2017). Variation of young adolescent who began giving birth before the age of 20 years by country in LMICs are as follows: Tunisia $1 \%$, Central African Republic $49 \%$, Bangladesh 30\%, Latin America and Caribbean (Peru) 13\% and Honduras 24\% (The Guttmacher Institute, 2015b) According to Guttmacher Institute, in most countries more than $75 \%$ of young women give birth before they reach the age 20 and some is said to have received antenatal care from a skilled provider. However, fewer of these young women receive that care early in their pregnancies in LMICs and make the recommended minimum of four antenatal visits (The Guttmacher Institute, 2015b). In LMICs the percentage of young women attended by a skilled professional in LMICs range from: $13-94 \%$ in Africa, 30-100\% in Asia, $44 \%$ in Haiti and 79\% in Latin America and Caribbean (The Guttmacher Institute, 2015b).

\subsection{Barriers to Utilizing Maternal Healthcare Information by AGYW in LMICs}

In Africa, there are some factors that have been identified as hindrance for women not to deliver in a health facility such as: Access-cost, facilities not easily accessible, and services not up to standard, absence of female provider or absence of service delivery. Whereas a few of the reasons in Asia (Nepal) are oppositions from the husband or family or the understanding that this care is needless or not part of their customs. Reasons in Latin America and the Caribbean for not delivering in health facilities are: Access and cultural reasons (Institute, 2015).

Barriers to access sexual and reproductive health services affect young people excessively (IPPF, 2017; Svanemyr et al., 2015). These barriers has been singled out to be weak infrastructure in health, communications and transport, inconvenient locations and opening hours; security in the community, city or country; affordability of care; and lack of trained health staff due to geographical, economic or political factors, as well as other barriers (IPPF, 2017; Upadhyay et al., 2014). Some factors such as: the stigmatization of the youth sexuality and sexual pressure; parental consent for minors; gender inequality has also been identified as major obstacles for young girls to make informed decisions about their bodies, reproductive life and sexuality (IPPF, 2017; The Guttmacher Institute., 2015a).

According to UNESCO the young girls and women from the disadvantaged families are mostly at a higher risk to become pregnant or give birth before they reach the age of 18 compared to young girls and women from rich families (UNESCO, 2018). Young mothers aged between 15 and 19 are more vulnerable to complications of maternal morbidity and mortality compared to women aged between 20 and 24 years, mostly due to their infantile unique biological, sociological and economic status (Eniola et al., 2017). Adolescent girls that are pregnant do visit maternal health services facilities late compared to older women due to indecisiveness about their use and access to and use of medical services. Families (e.g. by in- laws, or through restrictive laws and policies related to age of consent to sexual intercourse and access to services) mostly do take decisions on their behalf as to when and where to seek medical services (Eniola et al., 2017).

Young people are not an identical group. There are some factors that hinder their access to sexual and reproductive health (SRH) services, access to education and life opportunities and their general well-being such as: Their family situation, socio-economic status, sex, ethnicity, race, human immunodeficiency virus (HIV) status, geographical 
location, religious and cultural beliefs, sexual orientation and gender identity and many other factors (UNESCO, 2018). Health providers' attitudes and behaviour has become a hindering block to unmarried adolescent because some may refuse to provide sexual and reproductive health care due to marital status of the adolescents, or they may only provide care with parental permission because they disapprove youth sexual activity (IPPF, 2017; Marleen, 2015). Health Providers may not understand the sexual reproductive system of the young people that they might be sexually active especially when they seek SRH services and therefore neglect to offer appropriate counseling and services. Mostly when young people come to seek services they are being judged or stigmatized, break confidentiality, or only offer certain methods, therefore depriving young people of their rights to make voluntary and informed decisions (Haberland \& Rogow, 2015a). These type of behaviors may further discourage young people, particularly young women, to seek services they may need, delay access to treatment or use unqualified providers if they fear that they may be poorly treated or judged, or if they are concerned that their confidentiality and privacy will not be maintained (Haberland \& Rogow, 2015b; UNFPA, 2017b). According to UNESCO and WHO, barriers and challenges that hinder the access to quality maternal healthcare services should be identified at all levels of the health (UNESCO, 2017a; WHO, 2015a).

\section{Discussion}

Although health promotion interventions on maternal and new born health care are being implemented, there are specific guidelines and recommendations that need to be followed. The WHO guidelines on preventing early pregnancy and poor reproductive outcomes among adolescents in developing countries recommended a number of interrelated interventions to advocate for the adolescents pregnancy prevention among all stakeholders through interventions such as: information provision sexuality and health education, life skills building, contraceptive counselling and service provision and the creation of supportive environments (Smith et al., 2017; WHO, 2011). Even though there are many interventions that are focusing on the development of adolescent girls and young women, it will be imperative to involve other stakeholders to make the interventions successful. WHO documented some guidelines that stipulate some recommendations for action of which one stated that countries should integrate sexuality education into schools' curriculums to create awareness to adolescents, in order to reduce pregnancy rates (WHO, 2011). Interventions that are engaging with adolescents may be expanded to look at a broader picture so that not only adolescents and their families are involved, but community may also participate and collaborate with youth groups to develop an enabling environment, including fostering changes in broader social norms to encouraged improvements of care practices (WHO, 2011, 2015b, 2015c). Even though adolescent girls and young women should be allowed to make their own decisions, there should be policies and laws in place to guide them. Countries should develop and implement policies and laws which will create awareness on the rights of people under the age of 18 years, to guide them so that they can make their own decisions regarding sexual and reproductive health matters irrespective of their parental or spousal consent (Glinski et al., 2014; Marleen, 2015). Even though information on adolescent girls and young women is being provided, a lot still need to be done to transmit more information to young people to cater their health needs, more information regarding their health need to be shared to enable them to make informed decisions. Young people, need to be provided with quality education, training, health information and services to enable to make informed decisions. Furthermore, their rights need to be protected. They also need to be granted with opportunities to participate in decision making and to equip them for the future. This will enable them to participate in the affairs of their communities and contribute to economic development (UNFPA, 2014, 2017b; WHO, 2015a).

Based on these findings, it will be recommended that countries should adopt the WHO recommendations on health promotion interventions for maternal and new born care (MNC). It is also recommended that other stakeholders should be involved to make the interventions successful. The adolescent girls and young women should engage with other members of their communities to develop enabling environment. The legal framework should be strengthened to guide adolescent girls and young women in decision making. More information on adolescent girls and young women regarding their health needs to be shared to enable them to make informed decision. Quality education, training, health information, services as well as the rights protection and opportunities need to be provided. Youth development and life skills training need to be expanded. Comprehensive sexuality education needs to be provided to the adolescent girls and young women.

It is recommended that the study to assess the barriers faced by adolescent girls and young women during pregnancy to access and utilize maternal healthcare information in Ohangwena region of Namibia be conducted. We recommend that stakeholder engagement should be strengthened. Infrastructure development should be expanded such as mobile health (mHealth), text messages and health care technology (LeFevre et al., 2018). Community involvement and engagement in planning and decision making of adolescent girls and young women activities should be introduced. Political leaders should be committed to address challenges that hinder the 
development of adolescent girls and young women in their societies. Legal framework should be strengthened to enable policies and guidelines pertaining to adolescent girls and young women to be developed. It is also recommended that a framework to address future practice be recommended. Several studies conducted in different regions of the country did not address this research recommendation. Another factor, is that no study on accessing, utilization and effectiveness of maternal health care information provided to the adolescent girls and young women during pregnancy was conducted in Ohangwena region of Nambia where there is a high rate of teenage pregnancy. Figure 1 below illustrates solutions to the challenges to access and utilize maternal health care services by adolescent girls and young women.

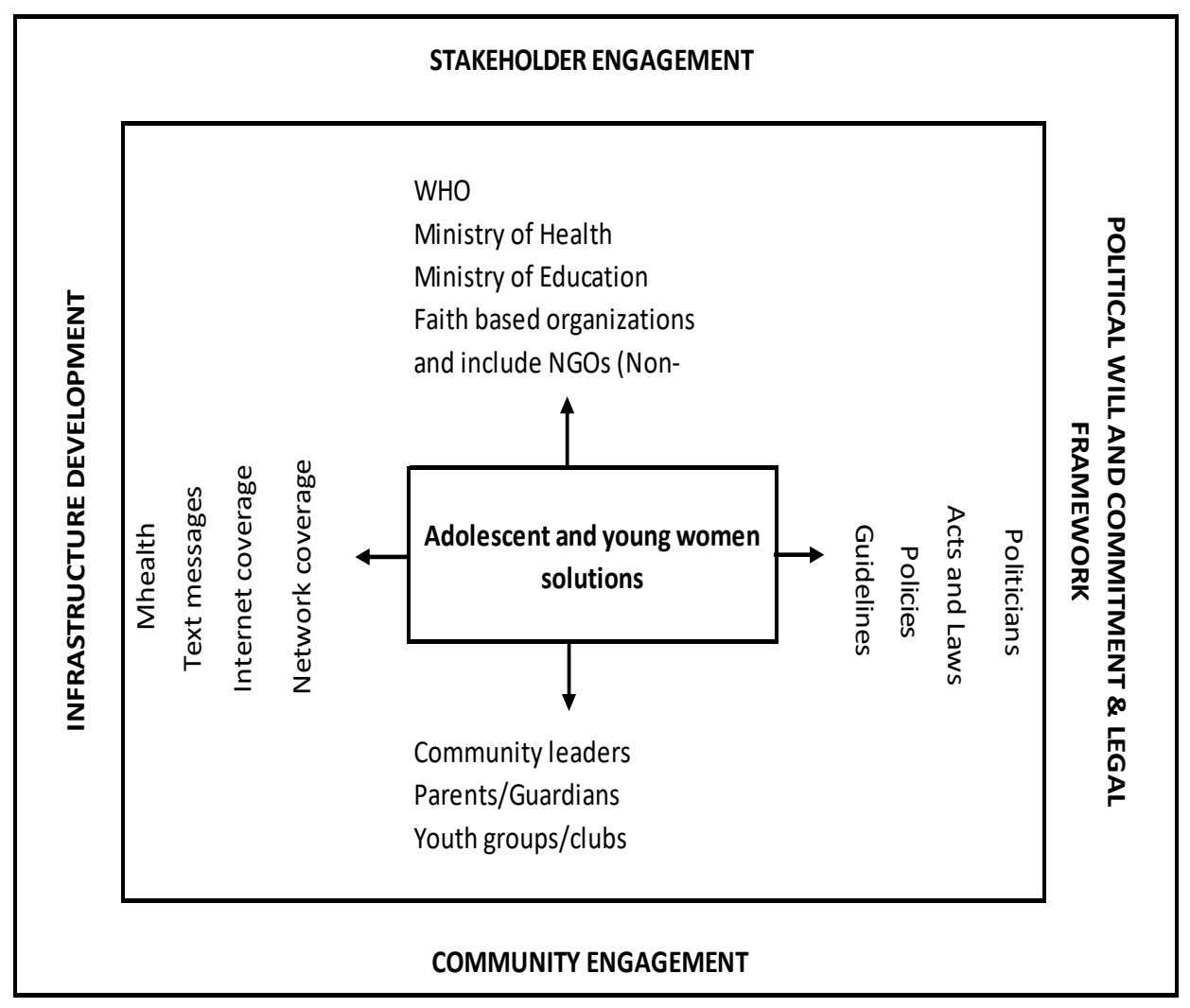

Figure 1. Framework to address challenges to access and utilize Maternal Health Care services by adolescents and young women

\section{Conclusion}

Lack of evidence on pregnant adolescents and their accessing, utilizing as well as the effectiveness of maternal health care information provided to them pose a risk to AGYW. They are at risk because of their biological, economic and sociological status, hence they are in dire need of assistance. Research to look at the barrier and challenges that hinder their accessing, utilization and effectiveness of maternal health care information provided to them during pregnancy will be of much assistance as this study will allow further recommendation for various interventions to alleviate the situation.

\section{Competing Interests Statement}

The authors declare that there are no competing or potential conflicts of interest.

\section{References}

Banke-Thomas, O. E., Banke-Thomas, A. O., \& Ameh, C. A. (2017). Factors influencing utilisation of maternal health services by adolescent mothers in Low-and middle-income countries: a systematic review. $B M C$ Pregnancy and Childbirth, 17(1), 65. https://doi.org/10.1186/s12884-017-1246-3

Chandra-Mouli, V., Svanemyr, J., Amin, A., Fogstad, H., Say. L., Girard, F., \& Temmerman, M. (2015b). Twenty 
Years After International Conference on Population and Development: Where Are We With Adolescent Sexual and Reproductive Health and Rights?. Journal of Adolescent Health, 56, S1-S6. https://doi.org/10.1016/j.jadohealth.2014.09.015

Charaborty, M. N., \& Sprockett, A. (2018). Use of family planning and child health services in the private sector: an equity analysis of 12 DHS surveys. International journal for equity in health. https://doi.org/10.1186/s12939-018-0763-7

Denno, D. M., Hoopes, A. J., \& Chandra-Mouli, V. (2015). Effective strategies to provide adolescent sexual and reproductive health services and to increase demand and community support. Journal of Adolescent Health. https://doi.org/10.1016/j.jadohealth.2014.09.012

Department of Health. (2017). National Adolescent and Youth Policy.

Eniola, O. B., Oluwabusayo, A., \& Ameh, C. A. (2017). Factors influencing utilisation of maternal health services by adolescent mothers in Low-and middle-income countries: a systematic review. BMC Pregnancy and Childbirth, 17(1), (65). https://doi.org/10.1186/s12884-017-1246-3

Ganchimeg, T., Ota, E., Morisaki, N., Laopaiboon, M., Lumbiganon, P., Zhang, J., . . Mori, R. (2014). Pregnancy and child outcomes among adolescent mothers:a World Health Organization multi country study. An international Journal of obstetrics and gynecology, 121(s1). https://doi.org/10.1111/1471-0528.12630

George, A. S., \& Branchini, C. (2017). Principles and processes behind promoting awareness of rights for quality maternal care services: a synthesis of stakeholder experiences and implementation factors. BMC Pregnancy Childbirth. https://doi.org/10.1186/s12884-017-1446-x

Glinski, A., Sexton, M., \& Petroni, S. (2014). Understanding the Adolescent Family Planning Evidence Base. International Center for Research on Women.

Gottschalk, L., \& Ortayli, N. (2014). Interventions to improve adolescents' contraceptive behaviors in low- and middle-income countries: A review of the evidence base. Contraception, 90. https://doi.org/10.1016/j.contraception.2014.04.017

Gottschalk, L. B. (2014). Interventions to improve adolescent friendly services.

Haberland, N., \& Rogow, D. (2015a). Sexuality Education: Emerging trends in Evidence and Practice. Journal of Adolescent Health, 56(1), S15-S21. https://doi.org/10.1016/j.jadohealth.2014.08.013

Hunter, B., \& Murray, S. (2017). Demand-side financing for maternal and newborn health: What do we know about factors that affect implementation of cash transfers and voucher programmes? BMC Pregnancy and Childbirth, 17. https://doi.org/10.1186/s12884-017-1445-y

Hunter, B. M., \& Murray, S. F. (2017). Demand-side financing for maternal and new born health: what do we know about factors that affect implementation of cash transfers and voucher programmes?. BMC Pregnancy Childbirth. https://doi.org/10.1186/s12884-017-1445-y

Hurst, T. E., Semrau, K., Patna, M., Gawande, A., \& Hirschhorn, L. R. (2015). Demand-side interventions for maternal care: evidence of more use, not better outcomes. BMC Pregnancy and Childbirth. https://doi.org/10.1186/s12884-015-0727-5

Institute, G. (2015). Adolescent Women's Need for and Use of Sexual and Reproductive Health Services in Developing Countries. Guttmacher Institute.

IPPF. (2017). IMAP Statement on youth peer provision models to deliver sexual and reproductive health services to young people.

Jones, E., Lattof, S. R., \& Coast, E. (2017). Interventions to provide culturally-appropriate maternity care services: factors affecting implementation. BMC Pregnancy and Childbirth, 17(1), 267. https://doi.org/10.1186/s12884-017-1449-7

Kuhlmann, A. K. S., Altmana, L., \& Galavottic, C. (2016). The importance of community mobilization in interventions to improve sexual, reproductive, and maternal health outcomes: A review of the evidence. Health Care For Women International, 37(10), 1028-1066. https://doi.org/10.1080/07399332.2016.1141911

Lassi, Z., Mansoor, T., Salam, R., Das, J., \& Bhutta, Z. (2014). Essential pre-pregnancy and pregnancy interventions for improved maternal, newborn and child health. Reproductive Health, 11, S2. https://doi.org/10.1186/1742-4755-11-S1-S2

Lassi, Z. S., Tarab, M., Salam, R. A., \& Bhutta, Z. A. (2014). Essential pre-pregnancy and pregnancy interventions 
for improved maternal, newborn and child health (Vol. 11). https://doi.org/10.1186/1742-4755-11-S1-S2

LeFevre, A., Cabrera-Escobar, M. A., Mohan, D., Eriksen, J., Rogers, D., Parsons, A. N., . . Coleman, J. (2018). Forecasting the Value for Money of Mobile Maternal Health Information Messages on Improving Utilization of Maternal and Child Health Services in Gauteng, South Africa: Cost-Effectiveness Analysis. JMIR mHealth and uHealth, 6(7). https://doi.org/10.2196/mhealth.8185

Marleen, T. E. A. (2015). Women's, Children's, and adolescents' health. The BMJ Today.

Melaku, Y. A., Weldearegawi, B., Tesfay, F. H., Abera, S. F., Abraham, L., Aregay, A., . . Kinsman, J. (2014). Poor linkages in maternal health care services evidence on antenatal care and institutional delivery from a community-based longitudinal study in Tigray region, Ethiopia. BMC Pregnancy and Childbirth. https://doi.org/10.1186/s12884-014-0418-7

Merrick, T. W. (2015). Making the case for investing in Adolescent Reproductive Health: A review of Evidence and PopPov Research Contributions UNESCO HIV and Health Education Clearinghouse.

Mheta, D., \& Mashamba-Thompson, T. (2017). Barriers and facilitators of access to maternal maternal servics for women with disabilities: Scoping reiview protocol. Systematic Reviews, 6(1), (99). https://doi.org/10.1186/s13643-017-0494-7

Miller, T., \& Smith, H. (2017). Establishing partnership with traditional birth attendants for improved maternal and newborn health: a review of factors influencing implementation. BMC Pregnancy Childbirth, (17). https://doi.org/10.1186/s12884-017-1534-y

Miltenburg, A. S., Roggeveen, Y., van Roosmalen, J., \& Smith, H. J. (2017). Interventions to promote birth preparedness and complication readiness: factors influencing implementation. BMC Pregnancy Childbirth. https://doi.org/10.1186/s12884-017-1448-8

Ministry of Health and Social Services \& UNICEF. (2017). Strengthening the adolescent component of national HIV programmes through country assessment. Report on Phase 2 of the Namibia "All in" Country assessment 2016. Republic of Namibia.

Plan International. (2017). Teenage Pregnancy. Working, Plan International.

PSI. (2017). Evidence Series. Sexual and Reproductive Health of Adolescets and Youth. Healthy lives, measurable results.

Smith, H., Portela, A., \& Marston, C. (2017). Improving implementation of health promotion interventions for maternal and newborn health: BioMed Central. https://doi.org/10.1186/s12884-017-1450-1

Svanemyr, J., Amin, A., Robles, O. J., \& Greene, M. E. (2015). Creating an Enabling Environment for Adolescent Sexual and Reproductive Health: A Framework and Promising Approaches. Journal of Adolescent Health, 56, S1-S4. https://doi.org/10.1016/j.jadohealth.2014.09.011

The Guttmacher Institute. (2015b). Adolescent Women's Need for and Use of Sexual and Reproductive Health Services in Developing Countries. Newyork, The Guttmacher Institute.

The Guttmacher Institute. (2015a). Adolescent Pregnancy and its Outcome Across Countries. Factsheet. Newyork, The Guttmacher Institute.

UNDP. (2018). Goal 3 Targets.

UNESCO. (2017a). Early and Unintended Pregnancy: Recommendations for the education sector.

UNESCO. (2018). International technical guidance on sexuality education.

UNFPA. (2014). Prioritizing investments.

UNFPA. (2017a). Every women, Every Child. Technical Guidance for Prioritizing Adolescent Health. Sustainable Development Goals.

UNFPA. (2017b). The safeguard young people programme.

UNFPA. (2017 b). UNFPA work on ASRH in Zimbabwe.

UNFPA. (2017a). Youth fight teen pregnancy with social media.

UNICEF. (2017). UNICEF DATA: Monitoring the situation of women and children.

Upadhyay, U. D., Gipson, J., Withers, M., Lewis, S., Ciaraldi, E. J., Fraser, A., . . Prata, N. (2014). Women's empowerment and fertility: A review of the literature. Journal of Social Science \& Medicine, 115, 111-120. 
https://doi.org/10.1016/j.socscimed.2014.06.014

USAID. (2016). A review of health financing in Namibia.

World Health Organisation [WHO]. (2011). WHO Guidelines on Preventing Early Pregnancy and Poor Reproductive Outcomes.

World Health Organisation [WHO]. (2014). Health for the Worlds Adolescents: A second chance in the second decade.

World Health Organisation [WHO]. (2014a). Adolescent Pregnancy Factsheet.

World Health Organisation [WHO]. (2015a). Every Woman, Every Child, Every Adolescent: Achievements and Prospect. The final report of the independent Expert Review Group on Information and Accountability for women's and Children's health.

World Health Organisation [WHO]. (2015b). Options for linking health interventions for adolescents with HPV vaccination.

World Health Organisation [WHO]. (2015c). WHO recommendations on health promotion interventions for maternal and newborn health. Geneva, WHO Press.

World Health Organisation [WHO]. (2017). Together on the road to Universal Health Coverage. A call for action (pp. 28). Geneva, WHO Press.

World Health Organisation [WHO]. Health Promotion.

\section{Copyrights}

Copyright for this article is retained by the author(s), with first publication rights granted to the journal.

This is an open-access article distributed under the terms and conditions of the Creative Commons Attribution license (http://creativecommons.org/licenses/by/4.0/). 